2021, Volume 16, ATEE 2020 - Winter Conference. Teacher Education for Promoting WellBeing in School. Suceava, 2020, pages: 490-506|

\section{Self-management Skills and Student Achievement - A Pilot Study}

\section{Maria Magdalena STAN1}

${ }^{1}$ University of Piteşti, Piteşti, România, magdalena.stan@,upit.ro
Abstract: The adaptation pressure of youths to a labor market with a low predictability degree determines the necessity of developing certain competences which can be easily transferrable and which can ensure the personal and professional success. We have considered non cognitive abilities (attitudes, emotions, behaviours) which proved to be significant predictors of success and mental health (Heckman, 2008) and which contribute significantly to a rise in emotional strength and to a wide range of adaptative strategies imposed by contemporary society (Opre et al., 2018). The speciality literature confirms the importance of non-cognitive abilities in the students' I pupils' academic success (Heckman et al., 2006; Heckman, 2008; Deming, 2015; Balica et al., 2016). The predictability degree of diverse non cognitive abilities over academic success is different as most studies do not supply relevant data about abilities such as self-efficacy, growth mindset or social awareness (Claro \& Loeb, 2019), while abilities like self-management defined as the ability to regulate one's emotions, thoughts, and behaviors in different situations (Duckworth \& Carlson, 2013) represents a good predictor of academic achievement (Blair \& Raver, 2015; Riggs et al., 2016). We consider self-management as being that umbrella construct which refers to abilities such as self-control, self-regulation, self-discipline, will power and selfpower (Duckworth \& Kern, 2011). Under the circumstances in which students with major risk abandonment participate in specific activities to develop personal, socio-emotional and learning management abilities, our study proposes to examine the variation of self-management abilities of students who participated in these activities and of students who did not participate in the activities and who are not prone to risk abandonment. Also, we wish to investigate if there is a relation between students' selfmanagement abilities and student achievement.

Keywords: soft skills, non-cognitive abilities, self-management, selfefficacy, student achievement

How to cite: Stan, M. M. (2021). Self-management Skills and Student Achievement - A Pilot Study. In O. Clipa (vol. ed.), Lumen Proceedings: Vol. 16. ATEE 2020 - Winter Conference.

Teacher Education for Promoting Well-Being in School. Suceava, 2020 (pp. 490-506). Iasi, Romania: LUMEN Publishing House. https://doi.org/10.18662/lumproc/atee2020/34 


\section{Introduction}

\subsection{Context}

In order to build a long-lasting and durable career in the context of an economic life characterized by dynamism, technologization and digitization, young people have to be able to adapt and apply creative and innovative solutions in their professional career path. The adaptation pressure for youths to a labor market with a low predictability degree determines the necessity of developing certain competences which can be easily transferrable and which can ensure the personal and professional success.

Within a competitive labour market, it is not sufficient to acquire specific professional competences (hard skills), technical from a certain domain of activity, one can get through the curricula of a program of studies (bachelor or master), but it is important to develop those competences (soft skills) which can be applied in any working environment. The specialty literature (Andrews \& Higson, 2008) includes the in soft skills sphere professionalism, the ability to cope with uncertainty, ability to work under pressure, ability to plan and think strategically, good written and verbal communication skills, capability to communicate and interact with others, either in teams or through networking, ICT skills, creativity and selfconfidence, reliability, willingness to learn and accept responsibility etc.

Soft skills are those abilities which contribute to success in any activity being dependent on the context and which exclude those specific technical or administrative abilities which ensure achievement in the respective activity. For the most part, these are called non- cognitive or personal abilities (adaptability, critical thinking, empathy, integrity, optimism, problem solving, decision making, goal setting, self-advocacy, proactivity, resilience, grit, teamwork, self-motivation, communication, positive attitude leadership, independence, self-regulation, creativity, time management, organization, professionalism in dress, work ethic, and punctuality), some of them being considered as part of personality traits and difficult to acquire in a formal background (Schulz, 2008), such as empathy or optimism. Levasseur (2013) presents a classification of soft skills according to the 
definition in the specialty literature: a. personal (self-awareness), b. interpersonal (communication), c. group (collaboration), and $d$. organizational (leadership). The value of soft skills represents a problem of global importance, being a component of employability and retention. Although companies offer their employees instruction programs for developing soft skills, considerable pressure is put on universities in order to develop these types of competences through the formation programs their students attend. The importance of soft skills is undisputable, the research confirming that professional achievement of employees at the working place is due to the contribution of such abilities to a great extent $75-85 \%$ (Robles, 2012).

Then if they contribute to such great extent to success in activity, how can we develop soft skills? In theory "soft skills development requires the personal motivation to learn and a much more complex ecological environment to support the personal interaction with others, which is necessary to foster the individual's development." (Levasseur, 2013, p. 569).

Even if the development of soft skills is more difficult to achieve, the specialty literatures describe (Robles, 2012; Isaacs, 2016; Cook, 2015) training programs which proved to be efficient within the formal environment of schools and universities. Levasseur (2013) considers that only certain soft skills can be acquired within some training programs or through the university curricula. The difficulty in forming them is due to their character, to a long time span of formation, which implies interaction, exercise, self-reflection and feedback. It is considered that the integration of some formation elements in the university curricula would contribute not only to the development of the soft skills necessary in socio-professional adaptation (Hagmann et al, 2003), but also would have immediate effects upon the students' academic success.

\subsection{Background of the study}

The interest for the study of the factors involved in academic adjustement is due mainly to the complexity of the phenomenon, whose long-term effects target a good professional adaptation and a high employability on the labour market. Onn a short-term it represents a strong 
predictor of academic adjustment, being involved in the process of dropout, mainly for the juniors in the first year, especially for those from vulnerable groups (financial problems, poor secondary school preparation, work and family conflict).

The approaches in defining student achievement are diverse, the concept being complex and multidimensional, referring to the acquisions built up by a student in a formal educational context and reflected in the value of educational outcomes transposed in grades, results at standardized tests or teachers' appreciations within evaluations. Operationally, academic success expresses the set of acquired knowledge, the development level of capacities and competences in academic context (Jeynes, 2008).

It is a well-known fact that the development of personal abilities during university studies has positive effects in the subsequent professional and personal life, as being easily transferrable. Mapping at students the individual differences which contribute to academic adjustment is essential in higher education since it represents a predictor of academic success and of prospective accomplishments for job opportunities (Strenze, 2007; Sanchez-Ruiz et al., 2016).

Undeniably, academic success of students is due at different degrees to different types of abilities (Cimatti, 2016; Koenig, 2011) - to cognitive skills (non-routine problem solving, critical thinking, systems thinking), interpersonal skills (complex communication, social skills, teamwork, cultural sensitivity, dealing with diversity), as well as to intrapersonal skills (self-management, time management, self-development, self-regulation, adaptability, executive functioning).

Most studies underline the fact that cognitive abilities associate to academic achievement (Deary et al., 2007; Di Fabio \& Palazzeschi, 2009; Laidra et al., 2007; Bratko et al., 2006) and employment status (Deary et al., 2004). The correlation between cognitive abilities and academic achievement is more specific for the age groups of pupils in primary and middle school cycle and less demonstrated for students in the universities (Leeson et al, 2008). This fact resulted most probably from the differences in measuring cognitive abilities but also from different markers of academic performance such as grade point average, seminar performance, scores from essays, 
absenteeism, etc. (Busato et al., 2000; Farsides \& Woodfield, 2002). Another argument about comparison and generalization of results of studies about the influence of cognitive abilities over academic achievement refers also to students' results which can be subjective due to different criteria set by teachers in evaluation students' knowledge (Peček et al., 2008; Smrtnik Vitulić \& Prosen, 2012).

Even if empirical studies evidence a strong correlation between cognitive abilities and academic achievement, a respectable variation from $51 \%$ to $75 \%$ in academic achievement is nevertheless unexplained by cognitive abilities (Rohde \& Thompson, 2007).

The interest for the study of non-cognitive factors in explaining student achievement is owed to the results in the specialty literature which underline that students' academic achievement depends on self-control or conscientiousness "a major reason for students falling short of their intellectual potential [is] their failure to exercise self-discipline" (Duckworth \& Seligman, 2005, p. 939). There are studies which prove that personality traits, emotion and motivation are predictors of academic achievement (Sanchez-Ruiz et al., 2016; Robbins et al., 2004)

We realize the difference cognitive versus non-cognitive in explaining student achievement from the perspective of the intervention plan, knowing that cognitive and non-cognitive abilities are interdependent and cannot be detached one from the other (Opre et al., 2018). Efficient psychoeducational interventions demonstrated in the specialty literature are those made upon non-cognitive factors as it is well known that intervention upon factors with a strong genetic component is difficult to perform. Demonstrated effects of interventions upon non-cognitive abilities (selfregulated learning) can have an impact over cognitive abilities (academic achievement).

\subsection{Theoretical framework}

In order to identify the predictors involved in academic achievement, the specialty literature suggests that the heuristic approach is the most appropriate, based on the empirical studies which demonstrate that noncognitive variables can determine student achievement directly or indirectly. 
In order to explain academic achievement, Robbins et. al. (2004) propose a composite social model which imply motivation, social engagement and academic-related skills. Motivation, as a complex construct can be explained through the achievement as a drive theory, thus motivation to achieve representing a strong predictor of academic performance. On the other hand, motivation can be explained in terms of achievement as goal theories, having as components self-efficacy and academic goals, both factors being strong predictors of academic performance.

The self-regulated learning model (Zimmerman, 1986; Schunk \& Zimmerman, 2003) explains the process of self-regulated learning with students through the contribution of the motivational constructs self-esteem and self -efficacy and of cognitive skills - self -regulated learning strategy (behavioral, motivational and metacognitive strategies).

The theoretical model we will follow is that developed by Farrington et. al. (2012) who conceptualized the way in which non-cognitive abilities such as academic behaviors (regularly attending class, arriving ready to work, going to class, doing homework), academic perseverance (grit, delayed gratification, self-discipline, self-control), academic mindset (sense of belonging, self-efficacy), learning strategies (time management, metacognition, self-regulated learning), and social skills (interpersonal skills, empathy, cooperation, assertion, responsibility), associate with academic performance depending on a socio-cultural context.

According to the authors academic behaviors is involved both directly and indirectly in academic achievement. Cognitive, non-cognitive and metacognitive factors are expressed through academic behaviours. Alongside behaviours like task completing, participation in learning activities, academic behaviour refers to solving the learning tasks at high quality standards, to effort mobilization to obtain academic performance. Academic perseverance refers both to the efforts the students make but also to the quality of the academic result. Academic perseverance includes implication, concentration and goal fulfilling the learning objectives behaviours, regardless the obstacles and distractions appeared. The structure of academic perseverance includes the perseverance to follow long-term objectives - the grit (consistency of interests and persistence of effort), as 
well as self-control (the ability to avoid impulsive behavior and fulfil shortterm obligations) (Duckworth et al., 2007). The studies confirm a much more relation between grades and self-control, than between grades and grit (Duckworth et al., 2007). The dimension academic mindset refers to beliefs, attitudes and perception ways in relation to learning and intellectual work. This dimension comprises factors such as students' sense of belonging in a school or classroom, students' belief in increasing their academic ability by their own effort, beliefs about intelligence, self-efficacy and the way students value an academic task, which correlates strongly with academic performance. Efficacy beliefs mediate the effect of skills and of other selfbeliefs on performance as they impact the level of students' effort, persistence, and perseverance (Farrington et al., 2012, p. 29). The importance of studying the contribution of academic mindset refers mainly to the efficient intervention modalities upon the determinant factors having an effect the improvement of academic performances.

Studies show that students who use self-regulation strategies (time management, self-regulated learning, goal setting and metacognition) tend to perform better in classroom tasks and activities.

Manifold conducted research demonstrate the role of social abilities in obtaining academic achievement. Most studies do not investigate the direct relation of socioemotional abilities but in combination with other non-cognitive factors. Meta-analysis carried out by Durlak et. al. (2011) upon SEL intervention programs admits their contribution to academic performance, with a size effect of 0.33 , without emphasizing the effect of social abilities directly (interpersonal skills, empathy, cooperation, assertion, responsibility).

In the proposed model, factors determine one another and intercorrelate reciprocally: "for example, mindsets have been shown to affect academic perseverance, which affects academic behaviors (e.g., completing work), which affects students' academic performance." (Farrington et al., 2012, p. 11).

The educational context reflects a large part of the variables, determining students' motivation: “...grading structures, feedback, and norms of behavior-are quite proximal to students' course performance and 
have been shown to affect academic mindsets, academic behaviors, and/or academic performance." (ibidem). The variable student background characteristic (gender, socioeconomic status, family characteristics, previous prerequisites, pre-existing mentalities etc) circumscribes to the term of academic identity, being strongly related to academic performance and acts as a real mediator of the educational context. The authors describe the functionality of the model in the socio-cultural context, which shape the structure of the educational mechanisms (opportunity structures, economic conditions which shape job opportunities, stereotypes and prejudices, inequalities etc.) and which contribute to the context of the learning environment.

SEL Theories affirm that if one intervenes upon personal competences such as self-awareness, self-management, social awareness, relationship skills, and responsible decision making, then students would engage in more positive social behaviors and have fewer problems with misconduct and less emotional distress, resulting in more engagement in the classroom and hence better test scores and grades (Greenberg et al., 2003).

Psychoeducational intervention upon some non-cognitive factors through efficient programs can bring forth an increase in academic performance and academic achievement. The intervention way implies the use of personal abilities regulating strategies reunited in the concept of selfmanagement.

Loosely, self-management represents "the ability to regulate one's emotions, thoughts, and behaviors in different situations" (Duckworth \& Carlson, 2013; Claro \& Loeb, 2019, p. 1). Self-management is described in studies as a strong predictor of academic achievement, choice-making skills and behavior modification competence (Heckman et al., 2006; Heckman, 2008; Deming, 2015; Balica et al., 2016). Additionally, self-management skills increase the use of transition strategies that facilitate transition planning from school period to adult life.

In a restricted sense, self-management refers to self-control, selfregulation, self-discipline, willpower, effortful control, ego strength, and inhibitory control, among others (Duckworth \& Kern, 2011). Also, CASEL (2018) defines self-management as being that ability to regulate emotions, 
thoughts, and behavior in order to delay gratification, motivate oneself, and work toward personal and academic goals.

Self-management represents a umbrella type multidimensional construct, which unifies those personal characteristics of the individual upon which it can act through a process of behavioural change and whose effects are positive on the level of adaptation and performances.

As concerns the operating mechanism, self-management represents the monitorization of own behaviour to which evaluation and own behaviour registration are added. In the process of self-management an important role is played by the assessment of self-evaluation accuracy. This can be done through comparing self-evaluations and evaluations of an external evaluator (teacher, counsellor, peer). Behaviour strength intervenes in the process of self-management only when self-evaluations match those of the external evaluator.

The results of the studies which analyzed the effects of personal selfmanagement demonstrated effects in reducing undesirable behaviors, increasing classroom preparedness, homework completion (GureaskoMoore et al., 2006), and academic performance (Barry \& Messer, 2003).

Measurement of self-management is not straightforward (Claro \& Loeb, 2019). In our research we shall choose a questionnaire -based measuring due to a better convergent validity (Duckworth \& Kern, 2011).

\section{Research questions/Aims of the research}

Our study proposes to underline the differences among the students who participated to a program of developing personal, socio-emotional and learning management abilities in issues concerning self-management and academic adjustment. Self- efficacy could explain the differences among students from the vulnerable group as compared to non-vulnerable students. Another goal of the research is to emphasize if there is a relation between the self-management and student achievement abilities.

\section{Research methods}

\subsection{Participants}


The sample is made up of 107 students, from the1-st year of the University of Pitesti, (Nmale $=28$, Nfemale $=79)$. The category of students from the vulnerable group consists of 62 students who have a graduation score at the baccalaureate exam lower than grade 7 (Nmale $=15$, Nfemale $=$ 47), of whom 62 students belong to disadvantaged socio-economic groups: 34 students whose income is lower than the minimum wage; 42 students who live in the rural area. The group of non-vulnerable students consists of 45 students, of whom 20 students have a lower income than the minimum wage and 25 with the domicile in the rural area.

\subsection{Materials and instruments}

a.Self-Control and Self-Management Scale - SCMS, adaptation (Mezo, 2009): adaptive self-regulatory coping skills instrument measures the three independent processes: self-monitoring - SM (6 items, $\alpha=.80)$, selfevaluating $-\mathrm{SE}$ (5 items, $\alpha=.73$ ), and self-reinforcing - SR (5 items, $\alpha$ $=.81)$. Cronbach's Alpha for the total scale is .87. The scoring of the SCMS and the three subscales was set on a six-point Likert scale, and the anchors adopted for score reporting are zero to five.

b.Self- efficacy for academic achievement - adaptation (Bong, 2001). This scale was used to assess students' self-perception of how competent they were in the academic field. The instrument has 7 items, $\alpha=0.83$. All response scales ranged from 1 (not at all true) to 5 (very true).

c.Academic achievement has been measured as an average of the grades obtained by students at the disciplines from the curricula of the study program at the end of the 1 -st year.

\subsection{Procedure}

At the beginning of the academic year 2018, we selected the students who fall in the category of vulnerable students (graduation score at the baccalaureate lower than 7, membership of the disadvantaged socioeconomic group, in which the income per family member is lower than the minimum wage and the rural background place of residence). Based on their own options the students from the vulnerable group participated to a support program which included remedial learning activities in order to 
acquire the prerequisites necessary to cover the contents of the 1-st year curricula, for the learning management, personal abilities management, for communication and socio-emotional abilities. Students participated in the program for a period of 20 weeks.

At the end of the implementation period, evaluation tools for selfmanagement and self- efficacy abilities have been applied to students from the vulnerable and non-vulnerable groups.

\section{Results}

The results processed by means of SPSS show the following aspects:

a.There is a significant correlation between the baccalaureate score and academic achievement, for the vulnerable group $\left(\mathrm{r}=0.418^{* *}, \mathrm{p}=0.001\right)$, as well as for the non-vulnerable one ( $\left.\mathrm{r}=0.787^{* *}, \mathrm{p}=0.001\right)$; thus the results obtained by the vulnerable group at the baccalaureate $(\mathrm{m}=6.63, \mathrm{SD}=0.42)$ associate significantly with the results obtained by students at the end of the first year of studies. $(\mathrm{m}=7.80, \mathrm{SD}=0.53)$. We have noticed a stronger relation between the results obtained at the baccalaureate by the nonvulnerable group $(\mathrm{m}=8.53, \mathrm{SD}=0.72)$ and the results obtained by students at the end of the first year of studies $(\mathrm{m}=9.10, \mathrm{SD}=0.70)$.

b. The presence of significant relations between the components selfmanagement and academic achievement, respectively between self- efficacy and academic achievement at students

Table 1. Relation among academic achievement, self- efficacy, self- management, self- monitoring, self- evaluating, and self- reinforcing

\begin{tabular}{lcccccc}
\hline Variables & $(1)$ & $(2)$ & $(3)$ & $(4)$ & $(5)$ & $(6)$ \\
\hline Academic & 1 & .137 & .0180 & -0.91 & .181 & $0.320^{* *}$ \\
achievement (1) & & & & & & \\
Self -efficacy (2) & & 1 & $.785^{* *}$ & $.502^{* *}$ & $.578^{* *}$ & $.513^{* *}$ \\
Self- management (3) & & & 1 & $.624^{* *}$ & $.662^{* *}$ & $.716^{* *}$ \\
Self-monitoring (4) & & & & 1 & .170 & .060 \\
Self-evaluating (5) & & & & & 1 & $.421^{* *}$ \\
Self-reinforcing (6) & & & & & & 1 \\
\hline
\end{tabular}


c.The existence of a non-significant relation as concerns selfmanagement between the students from the vulnerable group $(\mathrm{m}=64.92, \mathrm{SD}$ $=6.94)$ and students from the non-vulnerable one $(\mathrm{m}=62.84, \mathrm{SD}=8.43)$, test $\mathrm{t}$ for different samples $\left(\mathrm{df}_{105}\right)=1.39$, sig. $\left.=0.167\right)$. As concerns the mechanisms of the self-management construct significant relations can be observed between the group of vulnerable students $(\mathrm{m}=22.85, \mathrm{SD}=4.338)$ and the non-vulnerable group of students $(\mathrm{m}=19.40, \mathrm{SD}=3.928)$. As regards self- monitoring, there is a better capacity of self- monitoring of those in the vulnerable group. These results can be obtained due to vulnerable group students' participation to activities of personal development, learning management, personal and socio-emotional competences. We did not detect significant differences between the two groups in point of self-evaluating and self -reinforcing. The two mechanisms through which self-management manifests activate themselves much harder, as they need a long period for exercising and learning.

d.The presence of a significant relation as concerns self- efficacy in the vulnerable group $(\mathrm{m}=29.97, \mathrm{SD}=4.45)$ as compared to the nonvulnerable one $(m=27.82, S D=6.05)$. It seems that students from the vulnerable group manifest better abilities of self- efficacy: test $t$ for different samples $\left(\mathrm{df}_{105}\right)=2.11$, sig. $\left.=0.003\right)$.

e.The differences in the academic achievement scores are significantly higher for the vulnerable group $(\mathrm{m}=7.80, \mathrm{SD}=0.53)$ as compared to the non-vulnerable one $(\mathrm{m}=9.10, \mathrm{SD}=0.70)$, isolating the contribution of previous academic performances obtained by both groups at the baccalaureate exam. The statistic procedure used is the test ANCOVA $(\mathrm{F}=135.529, \mathrm{p}=0.000, \mathrm{R}$ square $=0.723$, partial $\mathrm{Eta}=0.723)$.

f.The differences for self-management scores are significantly higher for the vulnerable group $(\mathrm{m}=64.92, \mathrm{SD}=6.94)$, compared to the nonvulnerable group $(\mathrm{m}=62.84, \mathrm{SD})$, isolating the effect self- efficacy $(\mathrm{F}=83.896, \mathrm{p}=0.000, \mathrm{R}$ square $=0.617$, partial $\mathrm{Eta}=0.617)$

\section{Discussions}

The issue of self-efficacy in explaining the differences among students as regards their academic outcomes represents one of the objectives 
of our study. The analysis carried out reveals the fact that the level of selfefficacy is low at students from the vulnerable group, which explains the poor results at the baccalaureate exam on one hand and on the other hand the low academic grades at the end of the first school year. An explanation for the low level of self -efficacy is the fact that students perceive the learning tasks as being much more difficult than they really are, which induce stress and anxiety (Byrne et al., 2014). In the case of our study group, the fact that students participated to self-management activities determined a quick and specific feedback from teachers, which resulted in students' real perception of their own abilities and competences. Self- efficacy represents an individual factor which propels internal mechanisms of self-monitoring, self-evaluating, and self-reinforcing in order to manage the challenges of the learning tasks.

The development and launching of these mechanisms through specific educational programs which combine not only the intrapersonal and interpersonal abilities but also the cognitive ones lead to a fulfilment of academic goals and to academic performance.

The approach in studying the relation between self-management and academic achievement must not be exhaustive. In order to trigger students' motivation, one has to set goals, develop positive beliefs in their abilities through learning how to use different types of time management strategies, social and physical environment management strategies in order to control the factors which can affect learning and to achieve academic performance.

Even if the analyses from the specialty literature confirm that selfmanagement predicts achievement gains for students (as the relation with self-management is more powerful than with any other components of SEL - growth mindset, self-efficacy, and social awareness), our opinion is that without a challenging educational environment where teachers' strategy is based on authentic and constructive guiding and feedback, academic performance is relative.

\section{Conclusions}

Despite its limits due to the post-effect research design, to a low degree of data generalization, unrepresentative sampling, and to the 
unadapted tools for first year students, the present pilot study offers us many opportunities and directions, both methodologically and interventionally. The improvement of students' self- management abilities during the transitory period from the school type learning to the academic type learning through support psycho-educational programs has also an effect upon academic achievement. The study advances the idea that as early as university studies, one can intervene upon some non-cognitive abilities which can be transformed in soft skills, so necessary in present-day social and professional adaptation.

\section{References}

Andrews, J., \& Higson, H. (2008). Graduate Employability, 'Soft Skills’ Versus 'Hard' Business Knowledge: A European Study. Higher Education in Europe, 33(4), 411-422. https://doi.org/10.1080/03797720802522627

Balica, M., Benga, O., Caragea, V., David-Crisbăşanu, S., Goia, D., Horga, I., \& Iftode, O. (2016). Non-cognitive skill development in adolescents in Romania. Bucharest: UNICEF Romania.

Barry, L. M., \& Messer, J. J. (2003). A practical application of self-management for students diagnosed with attention-deficit/hyperactivity disorder. Journal of Positive Behavior Interventions, 5(4), 238-248. https://doi.org/10.1177/10983007030050040701

Blair, C., \& Raver, C. C. (2015). School Readiness and Self-Regulation: A Developmental Psychobiological Approach. Annual Review of Psychology, 66(1), 711-731. https://doi.org/10.1146/annurev-psych-010814-015221

Bong, M. (2001). Role of self-efficacy and task-value in predicting college students' course performance and future enrollment intentions. Contemporary Educational Psychology, 26(4), 553-570. https://doi.org/10.1006/ceps.2000.1048

Bratko, D., Chamorro-Premuzic T., \& Saks, Z. (2006). Personality and School Performance: Incremental Validity of Self- and Peer-Rating over Intelligence. Personality and Individual Differences, 41(1), 131-142. https://doi.org/10.1016/i.paid.2005.12.015

Busato, V. V., Prins, F. J., Elshout, J. J., \& Hamaker, C. (2000). Intellectual Ability, Learning Style, Personality, Achievement Motivation and Academic Success of Psychology Students in Higher Education. Personality and Individual Differences, 29(6), 1057-1068. https://doi.org/10.1016/s0191$\underline{8869(99) 00253-6}$ 
Byrne, M., Flood, B \& Griffin, J., (2014). Measuring the Academic Self-Efficacy of First-year Accounting Students. Accounting Education: An International Journal, 23(5), 407-423. https://doi.org/10.1080/09639284.2014.931240

CASEL. (2018). Core SEL Competencies. https://casel.org/core-competencies/

Cimatti, B. (2016). Definition, development, assessment of soft skills and their role for the quality of organizations and enterprises. International Journal for Quality Research, 10(1), 97-130.

Claro, S., \& Loeb, S. (2019). Self-Management Skills and Student Achievement Gains: Evidence from California's CORE Districts [Working paper]. Policy Analysis for California Education. https://edpolicyinca.org/publications/selfmanagement-skills-and-student-achievement-gains-evidence-california$\underline{\text { core-districts }}$

Cook, M. (2015). NWA job market calling for soft skills: Today's students lacking in qualities sought by employers. Arkansas Business, 32(6), 13.

Deary, I. J., Strand, S., Smith, P., \& Fernandes, C. (2007). Intelligence and educational achievement. Intelligence, 35(1), 13-21.

Deary, I. J., Whiteman, M. C., Starr, J. M., Whalley, L. J., \& Fox, H. C. (2004). The impact of childhood intelligence on later life: following up the Scottish mental surveys of 1932 and 1947. Journal of personality and social psychology, 86(1), 130-147.

Deming, D. (2015). The growing importance of social skills in the labor market. The Quarterly Journal of Economics, 132(4), 1593-1640.

Di Fabio, A., \& Palazzeschi, L. (2009). An In-Depth Look at Scholastic Success: Fluid Intelligence, Personality Traits or Emotional Intelligence? Personality and Individual Differences, 46(5-6), 581-585.

Duckworth, A. L., Seligman, M. E. P. (2005). Self-discipline outdoes IQ in predicting academic performance of adolescents. Psychological Science, 16, 939-944.

Duckworth, A. L., Peterson, C., Matthews, M. D., Kelly, D. R. (2007). Grit: Perseverance and passion for long-term goals. Journal of Personality and Social Psychology, 92, 1087-1101.

Duckworth, A. L., \& Kern, M. L. (2011). A meta-analysis of the convergent validity of self- control measures. Journal of Research in Personality, 45(3), 259-268.

Duckworth, A. L., Carlson, S. M. (2013). Self-regulation and school success. In B. W. Sokol, F. M. E. Grouzet, \& U. Müller (Eds.), Self-Regulation and Autonomy: Social and Developmental Dimensions of Human Conduct. Cambridge University Press.

Durlak, J. A., Weissberg, R. P., Dymnicki, A. B., Taylor, R. D., \& Schellinger, K. B. (2011). The impact of enhancing students' social and emotional learning: A meta-analysis of school-based universal interventions. Child Development, 82(1), 405-432. 
Farrington, C. A., Roderick, M., Allensworth, E., Nagaoka, J., Keyes, T. S., Johnson, D. W., \& Beechum, N. O. (2012). Teaching adolescents to become learners: The role of noncognitive factors in shaping school performance- $A$ critical literature review. Consortium on Chicago School Research.

https://www.kipp.org/wp-

content/uploads/2016/11/Teaching Adolescents to Become Learners.p $\underline{\mathrm{df}}$

Farsides, T., \& Woodfield, R. (2002). Individual Differences and Undergraduate Academic Success: The Roles of Personality, Intelligence and Application. Personality and Individual Differences, 34(7), 1225-1243.

Greenberg, M. T., Weissberg, R. P., O’Brien, M. U., Zins, J. E., Fredericks, L., Resnik, H., \& Elias, M. J. (2003). Enhancing school-based prevention and youth development through coordinated social, emotional, and academic learning. American Psychologist, 58(6-7), 466-474.

Gureasko-Moore, S., Dupaul, G. J., White, G. P. (2006). The effects of selfmanagement in general education classrooms on the organizational skills of adolescents with ADHD. Behavior Modification, 30(2), 159-183.

Hagmann, J., Almekinders, C., Bukenya, C., Guevara, F., \& Halemichael, A. (2003) Developing 'soft skills' in higher education. Participatory Learning and Action, 48, 21-28.

Heckman, J. (2008). Schools, Skills and Synapses. Economic Inquiry, 46(3), 289-324.

Heckman, J. J., Stixrud, J. A., \& Urzua, S. (2006). The Effects of Cognitive and Noncognitive Abilities on Labor Market Outcomes and Social Behavior [Working Paper 12006]. NBER Working Papers 1 2006, National Bureau of Economic Research, Inc. https://doi.org/10.3386/w12006

Isaacs, D. G. (2016). Hard jobs take soft skills. The Lane Report, 31(5), 26-29.

Jeynes, W. H. (2008). A meta-analysis of the relationship between phonics instruction and minority elementary school student academic achievement. Education and Urban Society, 40(2), 151-166.

Koenig, J. A. (2011). Assessing 21st century skills: summary of a workshop. The National Academies Press.

Laidra, K., Pullmann, H., \& Allik, J. (2007). Personality and Intelligence as Predictors of Academic Achievement: A Cross-Sectional Study from Elementary to Secondary School. Personality and Individual Differences, 42(3), 441-451.

Leeson, P., Ciarrochi, J., \& Heaven, P. C. L. (2008). Cognitive Ability, Personality, and Academic Performance in Adolescence. Personality and Individual Differences, 45(7), 630-635.

Levasseur, R. E. (2013). People skills: developing soft skills_ a change management perspective. Interfaces, 43(6), 566-571. 
Mezo, P. G. (2009). The self-control and self-management scale (SCMS):

Development of an adaptive self-regulatory coping skills instrument. Journal of Psychopathology and Behavioral Assessment, 31(2), 83-93

Opre, A, Benga, O., \& Dumulescu, D. (2018). Analiza practicilor psihoeducationale privind dezvoltarea abilitatilor non-cognitive la copii si adolescenti. Alpha MDN Publishing House.

Peček, M., Zuljan, M. V., Čuk, I., \& Lesar, I. (2008). Should Assessment Reflect Only Pupils' Knowledge? Educational Studies, 34(2), 73-82.

Riggs, N. R., Greenberg, M. T., Kusché, C. A., \& Pentz, M. A. (2006). The mediational role of neurocognition in the behavioral outcomes of a socialemotional prevention program in elementary school students: Effects of the PATHS curriculum. Prevention Science, 7(1), 91-102.

Robbins, S. B., Lauver, K., Le, H., Davis, D., Langley, R., \& Carlstrom, A. (2004). Do psychosocial and study skill factors predict college outcomes? A metaanalysis. Psychological Bulletin, 130(2), 261.

Robles, M. M. (2012). Executive perceptions of the top 10 soft skills needed in today's workplace. Business Communication Quarterly, 75(4), 453-465.

Rohde, T. E., \& Thompson, L. A. (2007). Predicting academic achievement with cognitive ability. Intelligence, 35, 83-92.

Sanchez-Ruiz, M. J., Khoury, J. E., Saadé, G., \& Salkhanian, M. (2016). NonCognitive Variables and Academic Achievement. In M. S. Khine, \& S. Areepattamannil (Eds.), Non-cognitive Skills and Factors in Educational Attainment. Contemporary Approaches to Research in learning Innovations. Sense Publishers.

Schulz, B. (2008). The importance of soft skills: education beyond academic knowledge. Journal of Language and Communication, 2(1), 146-154.

Schunk, D. H., \& Zimmerman, B. J. (2003). Self-regulation and learning. In W. M. Reynolds, \& G. E. Miller (Eds.), Handbook of psychology, Educational psychology (Vol. 7, pp. 59-78). John Wiley.

Smrtnik Vitulić, H., \& Prosen, S. (2012). Personality and cognitive abilities as predictors of university students' academic achievement. Drustvena istraživanja Journal for General Social Issues, 21(3), 715-732.

Strenze, T. (2007). Intelligence and Socioeconomic Success: A Meta-Analytic Review of Longitudinal Research. Intelligence, 35, 401-426.

Zimmerman, B. J. (1986). Development of self-regulated learning: Which are the key subprocesses? Contemporary Educational Psychology, 16, 307-313. 